Received: 13 February 2018

Accepted: 12 September 2018

Published online: 16 October 2018

\section{IgG-mediated immune suppression in mice is epitope specific except during high epitope density conditions}

\author{
Hui Xu(D, Lu Zhang \& Birgitta Heyman
}

Specific IgG antibodies, passively administered together with erythrocytes, suppress antibody responses against the erythrocytes. Although used to prevent alloimmunization in Rhesus (Rh) D-negative women carrying RhD-positive fetuses, the mechanism behind is not understood. In mice, IgG suppresses efficiently in the absence of $\mathrm{Fc} \gamma$-receptors and complement, suggesting an Fcindependent mechanism. In line with this, suppression is frequently restricted to the epitopes to which IgG binds. However, suppression of responses against epitopes not recognized by Ig G has also been observed thus arguing against Fc-independence. Here, we explored the possibility that non-epitope specific suppression can be explained by steric hindrance when the suppressive lg $G$ binds to an epitope present at high density. Mice were transfused with IgG anti-4-hydroxy-3-nitrophenylacetyl (NP) together with NP-conjugated sheep red blood cells (SRBC) with high, intermediate, or low NP-density. Antibody titers and the number of single antibody-forming cells were determined. As a rule, IgG suppressed NP- but not SRBC-specific responses (epitope specific suppression). However, there was one exception: suppression of both IgM anti-SRBC and IgM anti-NP responses occurred when high density SRBC-NP was administered (non-epitope specific suppression). These findings answer a longstanding question in antibody feedback regulation and are compatible with the hypothesis that epitope masking explains IgG-mediated immune suppression.

Passive administration of specific antibodies together with the antigen they recognize can result in dramatic changes in the antibody response as compared to administration of antigen alone (reviewed in $^{1-3}$ ). This so called antibody feedback regulation can be either positive, resulting in several 100-fold stronger antibody responses, or negative, resulting in more than $99 \%$ suppression. The most thoroughly studied feedback regulation is IgG-mediated suppression of antibody responses against erythrocytes. The suppressive ability of IgG has been applied clinically to prevent alloimmunization of $\mathrm{RhD}$-negative women against transplacentally transferred $\mathrm{RhD}$-positive fetal erythrocytes ${ }^{4-6}$. A common experimental approach when trying to elucidate the mechanism behind IgG-mediated immune suppression, has been to immunize mice intravenously with sheep red blood cells (SRBC) or haptenated SRBC ${ }^{7-11}$, or, more recently, with mouse erythrocytes expressing human blood group antigens as transgenes ${ }^{12-15}$. Polyclonal or monoclonal SRBC- or hapten-specific IgG were used as suppressive reagents.

The mechanism behind antibody-mediated immune suppression has been the subject of much speculation since its first discovery in the early 1900's ${ }^{16}$. Initially, it was postulated that the immune serum "masked" the antigen and prevented it from being recognized by immune cells via so called epitope masking. However, data suggesting that $\mathrm{F}\left(\mathrm{ab}^{\prime}\right)_{2}$ fragments were much less efficient immunosuppressors than intact IgG ${ }^{17-21}$ prompted the hypotheses that increased clearance of the IgG-antigen complexes via Fc-gamma receptors (Fc $\gamma \mathrm{Rs})$, or central inhibition of the B cell by co-crosslinking of the B cell receptor (BCR) and the negatively regulating Fc $\gamma$ RIIB ${ }^{22}$, were involved. The idea that IgG-mediated immune suppression was Fc-dependent received further support when many laboratories demonstrated that IgG can suppress in a non-epitope specific way: hapten-specific IgG, administered together with haptenated erythrocytes, suppresses the antibody response against erythrocyte epit-opes ${ }^{10,12,20,21,23,24}$, and monoclonal IgG specific for a certain epitope on SRBC suppresses antibody 


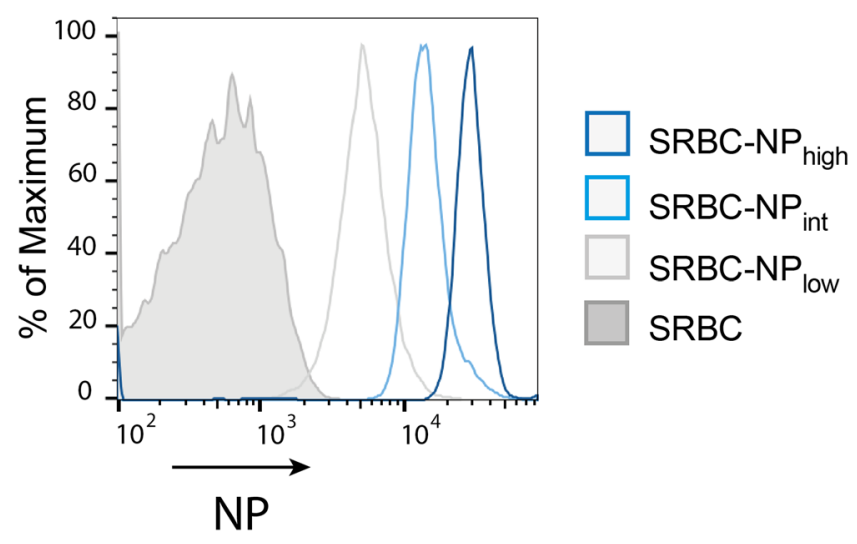

Figure 1. SRBC-NP with high, intermediate, or low density of NP epitopes. High $(180 \mu \mathrm{g} / \mathrm{ml})$, intermediate $(60 \mu \mathrm{g} / \mathrm{ml})$, or low $(20 \mu \mathrm{g} / \mathrm{ml})$ concentrations of NP- $\varepsilon$-aminocaproyl-OSu were incubated with SRBC as described in Materials and Methods. The relative amount of NP conjugated to the erythrocytes was determined by flow cytometry.

responses also to non-crossreacting epitopes ${ }^{8,25}$. In spite of reports demonstrating that $\mathrm{F}\left(\mathrm{ab}^{\prime}\right)_{2}$ fragments could suppress $^{26,27}$ and that IgG sometimes suppressed in an epitope-specific way ${ }^{9,28}$, the idea of Fc-dependence dominated. Therefore, the demonstration that IgG efficiently suppressed antibody responses to SRBC in mice lacking activating and/or inhibitory $\mathrm{Fc} \gamma \mathrm{Rs}^{10}$ was an unexpected finding and generated some debate at the time ${ }^{29-31}$.

Since then, several reports have confirmed that IgG-mediated immune suppression occurs in the absence of $\mathrm{Fc} \gamma \mathrm{Rs}^{13,15,32,33}$ and also in the absence of complement factor C3 (C3), complement factor C1q (C1q), or complement receptors 1 and $2(\mathrm{CR} 1 / 2)^{15,33}$. These findings suggest that IgG-mediated immune suppression takes place without involvement of the IgG Fc portion and, together with other experimental findings discussed below, suggest that epitope masking is an important explanation for IgG-mediated immune suppression. However, the undisputable existence of non-epitope-specific suppression is apparently in conflict with this idea because it implies dependence of the IgG Fc portion.

Recently, we found that administration to mice of IgG anti-4-hydroxy-3-nitrophenylacetyl (NP), or IgG anti-SRBC, together with SRBC-NP invariably resulted in epitope-specific suppression of the serum IgG response $^{11}$. In a majority of previous studies demonstrating non-epitope specific suppression, the read-out was a direct plaque forming cell (PFC) assay which detects single IgM (but not IgG) anti-SRBC-producing cells within a week after immunization.

We hypothesized that in order for non-epitope specific suppression to occur, two requirements must be fulfilled. First, IgM-responses must be assessed, and, second, the passively administered IgG must bind to an epitope present at high density. In this situation, IgG may be able to prevent B cells from recognizing both the epitopes to which the IgG itself binds (via epitope masking) and neighbouring epitopes (via steric hindrance). The question of Fc-dependence is of utmost importance for understanding the mechanism behind suppression and conflicting data exist. Therefore, we have here analyzed in detail the epitope-specificity of IgG-mediated immune suppression of IgM and IgG serum responses as well as of specific splenic B cell numbers. The results show that IgG always suppresses the response to its specific epitope, regardless of whether IgM or IgG responses are studied and regardless of epitope density. In addition, IgG can also suppress IgM responses to non-specific epitopes, provided that the specific epitopes (to which IgG binds) are present at high density. This suggests that steric hindrance rather than Fc-dependent functions explains non-epitope specific suppression and the data are compatible with the epitope masking hypothesis.

\section{Results}

IgG anti-NP suppresses IgM anti-NP responses at all NP densities. To test the hypothesis that IgGmediated immune suppression can be either epitope- specific (during low epitope density conditions) or nonepitope specific (during high epitope density conditions), SRBC with high, intermediate, or low density NP were generated (Fig. 1) and mice were immunized with the different SRBC-NP preparations \pm polyclonal IgG anti-NP. Five days after immunization, serum and spleen samples were obtained and NP-specific responses were assayed (Fig. 2).

C56BL/6 mice have a genetically restricted antibody response against NP, comprising mainly $\lambda 1$ light chains and the V186.2 segment of the VHJ558 gene family ${ }^{34}$. Therefore, NP-specific B cells can be identified as $\mathrm{B} 220^{+} \lambda 1^{+} \mathrm{NP}^{+}$cells $^{11}$. A representative gating strategy for mice immunized with SRBC-NP ${ }_{\text {high }}$, IgG anti-NP + SRBC-NP ${ }_{\text {high }}$, or IgG anti-NP alone is shown in Fig. 2A. Cells were first gated as B220 (not shown) and then, using CD95 and GL7 as markers, split into germinal center (GC) B cells (CD95 ${ }^{\text {high }}$ GL7 $7^{\text {high }}$ ) and non-GC $B$ cells (top row). The middle row shows GC and non-GC B cells expressing the $\lambda 1$ light chains and the bottom row $\lambda 1^{+}$GC and non-GC B cells binding to NP. The results, expressed as $\%$ of $\mathrm{NP}^{+} \lambda 1^{+}$GC and non-GC B cells of total $\mathrm{B} 220^{+}$cells, from one of four experiments is shown in Fig. 2B. In mice immunized with SRBC-NP, GC $\mathrm{B}$ cells (GL7 ${ }^{\text {high }} \mathrm{CD} 95^{\text {high }}$ ) and non-GC B cells were increased as compared to negative controls immunized with unconjugated SRBC or IgG anti-NP alone (Fig. 2B). In mice transfused with IgG anti-NP together with SRBC-NP, neither the GC- nor the non-GC NP-specific B cell populations increased but remained at the same level as in the 
A

SRBC-NP $P_{\text {high }}$
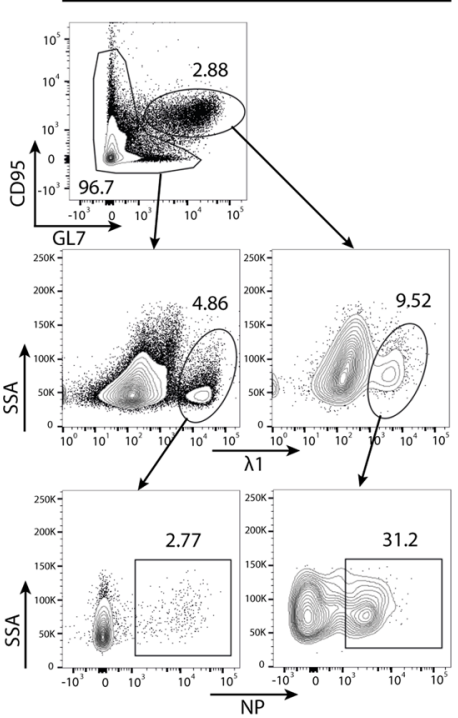
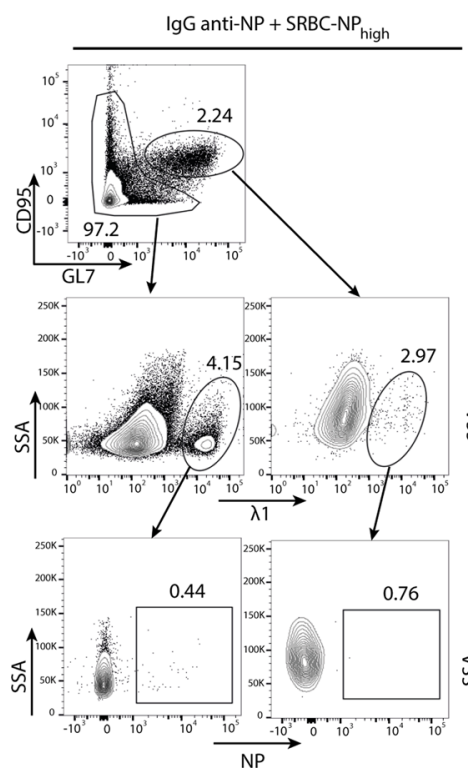
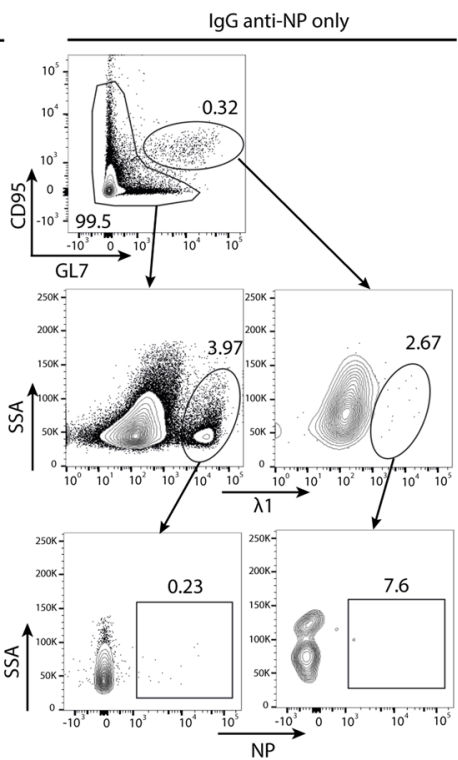

B

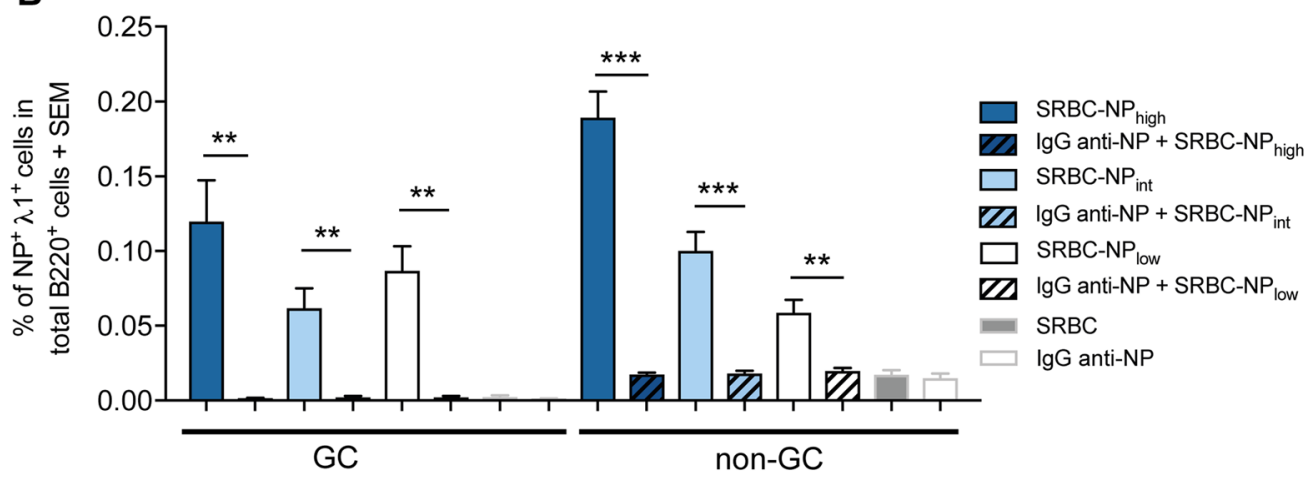

C

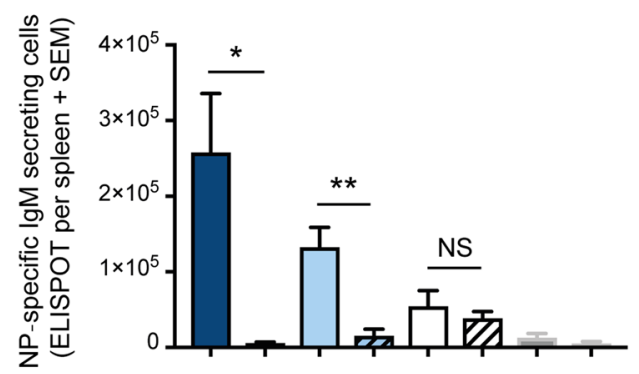

D

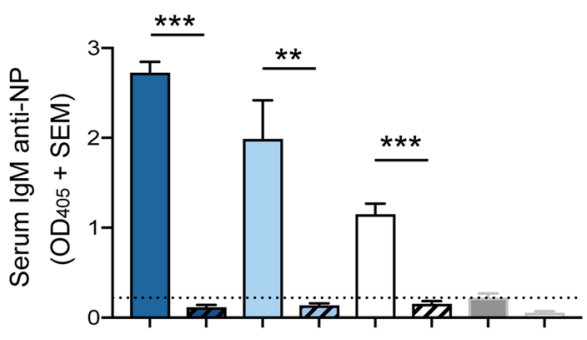

Figure 2. IgG anti-NP suppresses IgM anti-NP responses at all NP densities. C57BL/6 mice were immunized

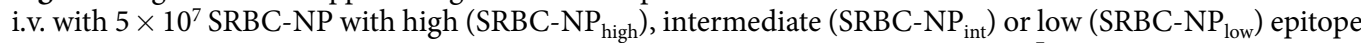
density with or without $30 \mu \mathrm{g}$ polyclonal IgG anti-NP. Mice immunized with $5 \times 10^{7}$ unconjugated SRBC or with $30 \mu \mathrm{g}$ IgG-anti NP only were used as controls. NP-specific immune responses were analyzed in spleen and serum samples obtained 5 days after immunization. (A) Cells were initially gated for $\mathrm{B} 220^{+}$cells. Representative flow cytometry gating for $\mathrm{B} 220^{+} \mathrm{GC}$ (defined as GL7 ${ }^{\text {high }} \mathrm{CD} 95^{\text {high }}$ ) and non-GC $\lambda 1^{+} \mathrm{NP}^{+}$cells from mice

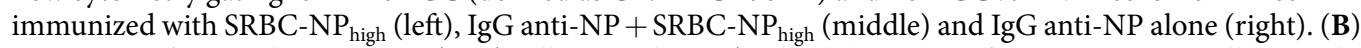
Frequency of GC and non-GC NP${ }^{+} \lambda 1^{+}$cells in total B220+ cells. (C) NP-specific IgM-secreting cells per spleen. (D) Serum IgM anti-NP levels (serum dilution in ELISA = 1:625). The dashed line indicates the mean value of mice immunized with unconjugated SRBC. Representative of four independent experiments with $4-5$ mice per group. $\mathrm{ns}=p>0.05,{ }^{*} p<0.05, * * p<0.01, * * * p<0.001$

negative control mice (Fig. 2B). Thus, IgG anti-NP suppresses the generation of NP-specific GC and non-GC B cells to low, intermediate as well as highly haptenated SRBC-NP.

Next, NP-specific IgM-secreting cells, from the same spleens as above, and serum IgM anti-NP obtained from the same mice, were analyzed. Regardless of NP density, IgG anti-NP suppressed the number of NP-specific 


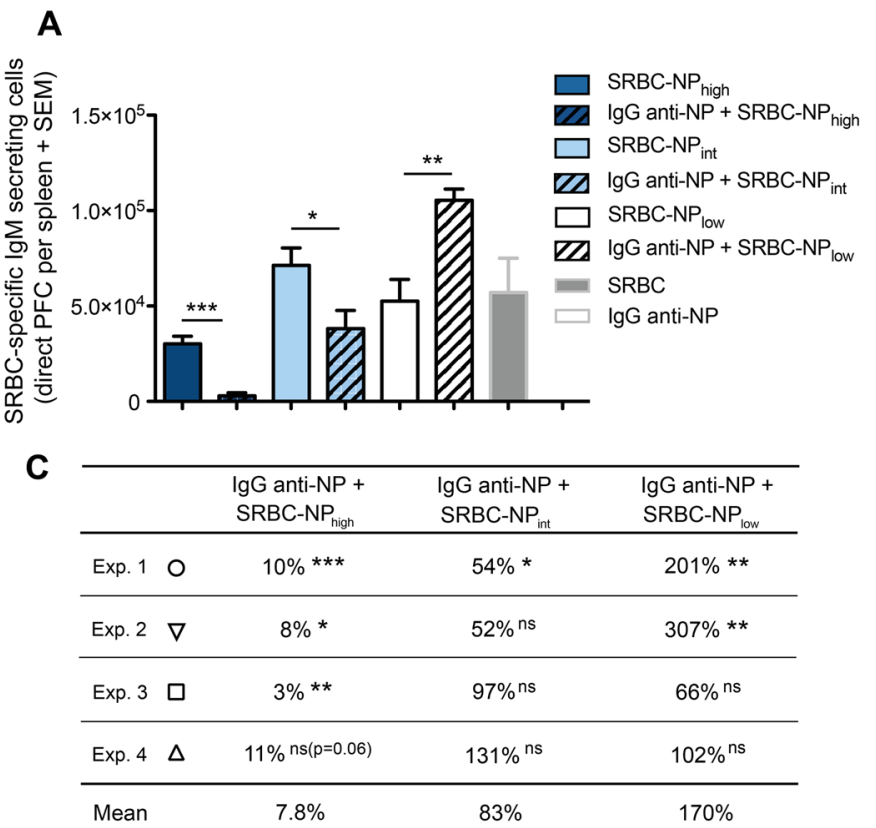

B

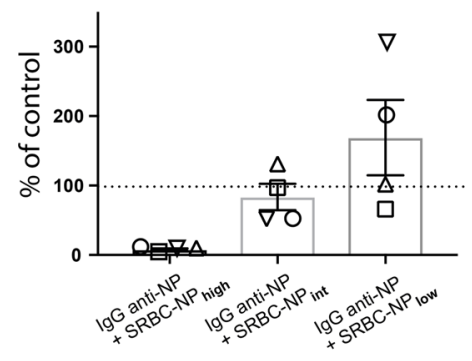

D

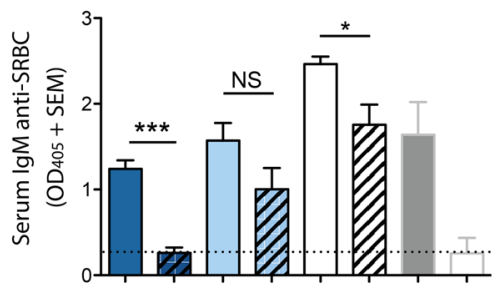

Figure 3. IgG anti-NP suppresses IgM anti-SRBC responses at high, but not at low, epitope density. SRBCspecific IgM responses were analyzed in the mice described in Fig. 2. (A) SRBC-specific IgM-secreting cells per spleen (=Exp 1 in $\mathbf{B}$ and $\mathbf{C})$. (B,C) Summary of the PFC results from all four experiments performed. Suppression is presented as the percentage of the control responses (number of PFCs in mice immunized with SRBC-NP alone, $100 \%$, dashed line) that remains in mice immunized with IgG anti-NP+ respective SRBC-NP. The mean of PFCs in the control groups (representing 100\%) were, in the order SRBC-NP $\mathrm{high}_{\text {int } / \text { low: }}: 30,080 / 71$, 300/52, 533 (Exp. 1); 24, 793/50, 960/39, 200 (Exp 2); 30, 267/73, 233/136, 027 (Exp. 3); 22, 308/33, 267/63, 967 (Exp 4). $p$ values represent comparisons between groups that received IgG anti-NP $+\mathrm{SRBC}-\mathrm{NP}_{\text {high/int/low }}$ and only SRBC-NP high/int/low. $_{\text {. }}$ Each experiment is shown with a different symbol. (D) Serum IgM anti-SRBC levels (serum dilution in ELISA =1:625). The dashed line indicates the mean value of mice immunized with IgG anti-NP alone. $\mathrm{ns}=p>0.05,{ }^{*} p<0.05, * * p<0.01, * * * p<0.001$.

IgM-secreting cells (Fig. 2C) and the IgM anti-NP levels in serum (Fig. 2D). Thus, IgG anti-NP administered with either high, intermediate, or low density SRBC-NP consistently suppressed IgM anti-NP responses and the number of $\mathrm{NP}^{+}$splenic B cells.

IgG anti-NP suppresses IgM anti-SRBC responses at high, but not at low, NP density. A crucial question was whether IgG anti-NP, administered together with SRBC-NP, could act in a non-epitope specific manner and suppress also SRBC-specific IgM responses. Splenocytes from the same mice as in Fig. 2 were analyzed for single IgM anti-SRBC-secreting cells in a direct PFC assay. Here, the NP-density on SRBC played a significant role for the outcome of the suppression. In the experiment shown in Fig. 3A (=Exp. 1 in Fig. 3C), IgG caused $90 \%$ suppression in mice immunized with SRBC-NP $\mathrm{high}_{\text {h }}, 46 \%$ suppression with SRBC-NP $\mathrm{P}_{\text {int }}$, and no

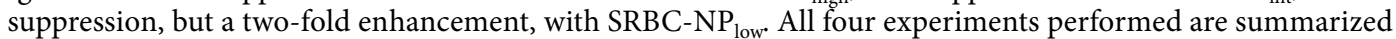
in Fig. 3B and C. IgG anti-NP suppressed the PFC response to SRBC-NP ${ }_{\text {high }}$ by $89-97 \%$, thus leaving $3-11 \%$ of the control response. The response to $\mathrm{SRBC}-\mathrm{NP}_{\text {int }}$ was moderately suppressed or unchanged and the response to $\mathrm{SRBC}-\mathrm{NP}_{\text {low }}$ was unchanged or enhanced.

IgM anti-SRBC in serum from these mice was assessed in ELISA (Fig. 3D). A major decrease was seen in mice transfused with SRBC-NP $\mathrm{Nigh}_{\text {h }}$ together with IgG anti-NP while the response in intermediate or low density groups was only marginally decreased. The IgM anti-SRBC was suppressed by IgG in the high density groups in all four experiments performed. In 5 out of 8 groups immunized with intermediate or low density SRBC-NP, IgG had no effect on the IgM levels. In the remaining 3 groups, the IgM levels were significantly decreased, but invariably the decrease was smaller than in the corresponding high density groups.

A possible explanation for the ability of IgG anti-NP to suppress both IgM anti-NP and IgM anti-SRBC responses at high NP density conditions would be that IgG anti-NP, binding to high density NP-epitopes (but not to low density NP-epitopes), sterically prevents B cells from binding not only to NP- but also to SRBC-epitopes. An indication that this is indeed the case is the fact that IgG anti-NP, incubated with SRBC with different NP-densities, impaired subsequent binding of IgG anti-SRBC to the erythrocytes (Supplementary Fig. 1). The impairment was proportional to the NP density: the higher the NP density the higher the impairment (i.e. the less IgG anti-SRBC could bind). Presumably, this impairment is even more efficient in vivo where naive SRBC-specific $\operatorname{IgM}^{+}$B cells, instead of serum IgG, would have to compete with high affinity IgG anti-NP for access to SRBC.

In summary, efficient suppression ( $>89 \%)$ of the IgM anti-SRBC PFC responses occurred with high but not with intermediate or low density SRBC-NP. This agrees with earlier observations of non-epitope specific 

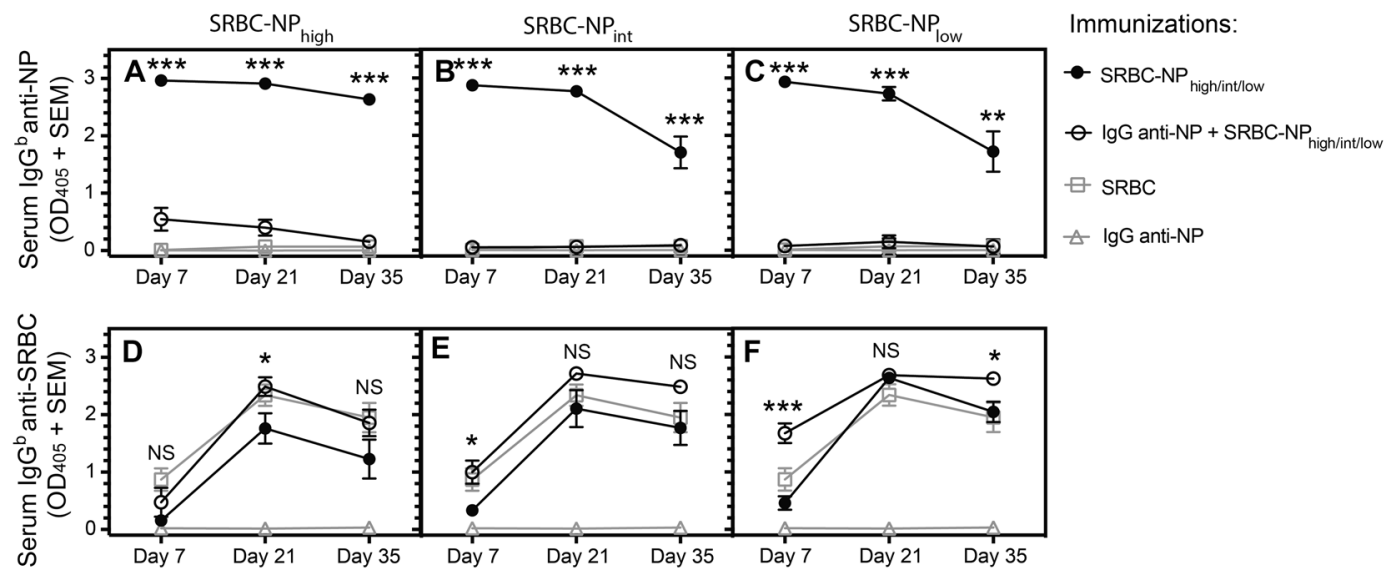

Figure 4. IgG anti-NP suppresses IgG anti-NP but not IgG anti-SRBC responses at all NP densities. C57BL/6 mice ( 5 per group) were immunized in the same way as described in Fig. 2. Serum samples were collected 7, 21, and 35 days after immunization and assayed for NP- and SRBC-specific IgG ${ }^{\mathrm{b}}$ levels (serum dilution in ELISA $=1: 625)$. $p$ values represent comparisons between groups that received IgG anti-NP $+\mathrm{SRBC}-\mathrm{NP}_{\text {high/int/low }}$ and only SRBC-NP $\mathrm{high} / \mathrm{int} / \mathrm{low}_{\mathrm{ns}}=p>0.05,{ }^{*} p<0.05, * * p<0.01, * * * p<0.001$.

suppression at high density ${ }^{24,35}$ and with the finding that monoclonal IgG antibodies, recognizing different epitopes on an antigen, have an additive suppressive effect when administered as a blend ${ }^{14,36}$. Blocking experiments in vitro directly suggested that this could depend on steric hindrance by the suppressive IgG.

IgG anti-NP suppresses IgG anti-NP but not IgG anti-SRBC responses at all NP densities. IgG anti-SRBC and IgG anti-NP, administered together with SRBC-NP, was previously shown to suppress serum IgG responses in a strictly epitope-specific way ${ }^{11}$. In light of the finding that epitope density was crucial to reveal non-epitope specific suppression of IgM responses (Fig. 3), we here re-addressed the epitope specificity of suppression of IgG responses. The same NP conjugation ratios as in Figs 2 and 3 were used. In analogy with previous observations $^{11}$, IgG anti-NP administered together with SRBC-NP of either of the three epitope densities suppressed the IgG responses against NP but not against SRBC (Fig. 4). Thus, suppression of the IgG response was epitope specific. At a few time points, IgG enhanced the non-epitope specific IgG anti-SRBC response (Fig. 4DF), thus resembling the effects occasionally seen on the IgM anti-SRBC responses (Fig. 3). Although the overall immunoregulatory role of IgG administered together with erythrocytes is suppressive, enhancement has been noted by a few previous workers $9,37,38$.

\section{Discussion}

The aim of the present study was to find out whether the well documented non-epitope specific suppression by IgG could be reconciled with the equally well documented unperturbed suppression in mice lacking Fc $\gamma$ Rs. While the former observations suggested Fc-dependence, the latter argued against this. To clarify the specificity of IgG-mediated immune suppression, we analyzed several parameters of B cell responses in the same mice. Our results demonstrate that IgG in most situations suppressed only epitope specific (i. e. NP) responses. However, there was one important exception. When SRBC-NP with high NP-density was administered, IgM anti-SRBC responses, in addition to IgM anti-NP responses, were suppressed by IgG anti-NP. Thus, during these specific conditions, IgG suppressed non-epitope specific (i. e. also SRBC) responses (Fig. 5). Because control mice immu-

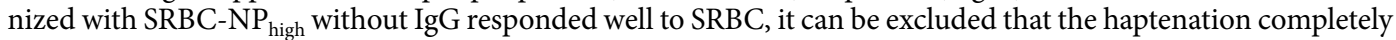
destroyed SRBC epitopes. Therefore, lack of immunogenic SRBC epitopes cannot explain the suppressed IgM anti-SRBC response in mice immunized with IgG anti-NP $+\mathrm{SRBC}-\mathrm{NP}_{\text {high }}$ shown in Fig. 3. The data presented herein can explain previous, seemingly conflicting, results regarding epitope-specificity of IgG-mediated suppression. They show (i) that both epitope-specific and non-epitope specific suppression of IgM-responses exist, while suppression of IgG-responses is always epitope-specific, and (ii) that epitope density, rather than presence or absence of the IgG Fc portion, determines whether suppression of IgM-responses will be epitope-specific or non-epitope specific. Blocking experiments show that IgG anti-NP, binding to SRBC-NP with different NP densities, is able to impair subsequent binding of IgG anti-SRBC in a density-dependent fashion (Supplementary Fig. 1). This suggests that IgG anti-NP binding to NP-epitopes can sterically hinder also SRBC-specific B cells from binding to SRBC-NP provided the NP-epitopes are present at a high density. Thus, our findings provide an explanation for how IgG can induce either epitope-specific or non-epitope specific suppression and suggest that both are compatible with epitope masking.

An interesting question is why IgG suppresses $\operatorname{IgM}$, but not $\operatorname{IgG}$, responses in a non-epitope specific way during high epitope density conditions. B cells with IgG BCRs develop later in the antibody response and generally have higher affinity than B cells with IgM BCRs. Therefore, $\operatorname{IgG}^{+} \mathrm{B}$ cells may compete more efficiently than IgM+ $B$ cells with the transfused IgG and get access to neighbouring SRBC-epitopes. This would result in an IgG, but not an IgM, anti-SRBC response. Marginal zone B cells are known to respond to thymus-dependent as well as thymus-independent antigens entering the marginal zone from the blood ${ }^{39,40}$ and are presumably responsible for most of the early IgM anti-SRBC responses. A possibility is that intrinsic features of marginal zone B cells 

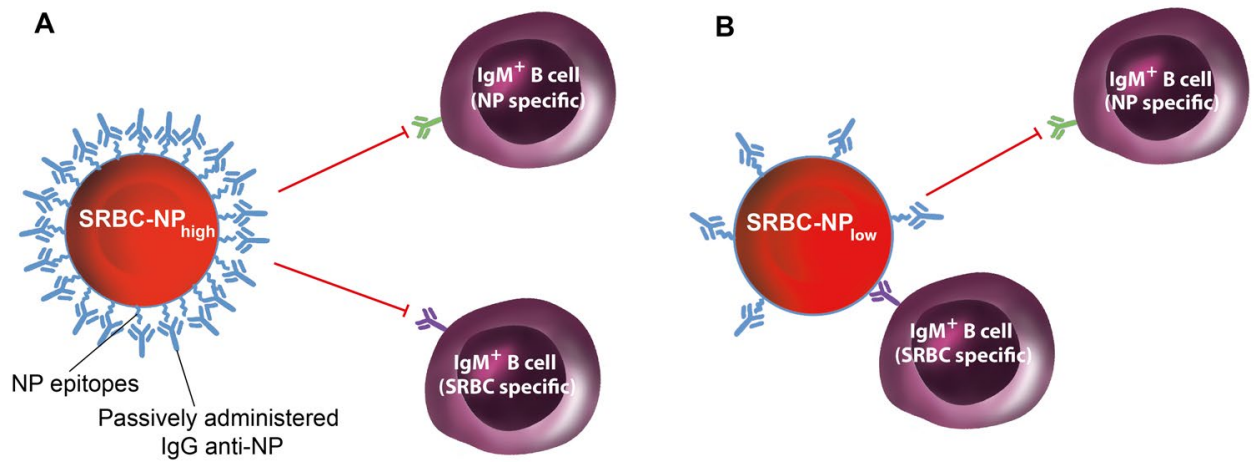

Figure 5. A model for IgG-mediated suppression of IgM responses at high and low epitope densities. (A) When NP is present at high density on the SRBC surface, IgG anti-NP will hide both NP epitopes and, due to steric hindrance, SRBC epitopes from recognition by $\operatorname{IgM}^{+} \mathrm{B}$ cells (which usually have low affinity). This prevents production of both IgM anti-NP and IgM anti-SRBC and will be noted as non-epitope specific suppression. (B) When NP is present at low density on the SRBC surface, IgG anti-NP will hide NP, but not SRBC, epitopes from recognition by $\operatorname{IgM}^{+}$B cells. This prevents production of IgM anti-NP but not of IgM anti-SRBC and will be noted as epitope-specific suppression.

render them less efficient than IgG-producing follicular B cells in competing with the transfused IgG anti-NP for SRBC determinants during high epitope density conditions. Yet another possibility would be that erythrocytes are fragmented over time and that small membrane pieces, exposing free SRBC-epitopes, become accessible to SRBC-specific IgG-switched B cells dominating later during the response. Because the NP-epitopes, unlike the SRBC-epitopes, are directly blocked by high affinity IgG anti-NP, neither IgG- nor IgM-producing NP-specific B cells will be able to outcompete the passively administered IgG.

Evidence of epitope-specificity of suppression, in combination with non-epitope specific suppression at high density conditions, is probably the most direct indication of an important role for epitope masking in immunosuppression. Importantly, many other observations are compatible with, although not formally proving, the epitope masking hypothesis. Efficient suppression occurs in the absence of complement and Fc $\gamma \mathrm{Rs}^{10,13,15,32,33}$. Not only intact IgG, but also $\operatorname{IgM}{ }^{41}, \operatorname{IgE}{ }^{10,42}$, and $\operatorname{IgG~F}\left(\mathrm{ab}^{\prime}\right)_{2}$ fragments ${ }^{10,26,27}$ can suppress. Suppression is more efficient with high than with low affinity $\operatorname{IgG}^{20,43}$. The suppressive capacity of SRBC-specific monoclonal or polyclonal antibodies correlates with the density of IgG bound to erythrocytes ${ }^{8,44}$ and non-epitope specific suppression requires high hapten density (Fig. 3$)^{24,35}$. Finally, the specific T cell responses are only marginally affected in mice where the antibody response is nearly completely suppressed ${ }^{10,24}$. This is to be expected because SRBC-IgG complexes would be endocytosed and presented as peptides to T cells even when the B cell epitopes are hidden.

On the other hand, some observations are not compatible with the epitope masking model. For example, the inability of $\operatorname{IgG~} \mathrm{F}\left(\mathrm{ab}^{\prime}\right)_{2}$ fragments to suppress ${ }^{17-21}$ does not fit with the model. It is not known why some investigators found that $\mathrm{F}\left(\mathrm{ab}^{\prime}\right)_{2}$ fragments were suppressive ${ }^{10,26,27}$ while others found that they were not ${ }^{17-21}$. One possibility is that $\mathrm{F}\left(\mathrm{ab}^{\prime}\right)_{2}$ fragments are eliminated faster than intact IgG owing to lack of binding to the protective neonatal Fc-receptor $(\mathrm{FcRn})^{45}$. This may have resulted in concentrations of $\mathrm{F}\left(\mathrm{ab}^{\prime}\right)_{2}$ fragments too low to induce suppression. Another observation that cannot be reconciled with epitope masking is the failure of IgG to suppress in double knock-out mice lacking C3 and all activating $\mathrm{F}_{\mathrm{c}} \gamma \mathrm{Rs}$ (Fc $\left.\gamma \mathrm{RI}, \mathrm{Fc} \gamma \mathrm{RIII}, \mathrm{Fc} \gamma \mathrm{RIV}\right)$ but retaining the inhibitory Fc $\gamma$ RIIB (suppression worked well in each single knock-out strain) ${ }^{15}$. This finding remains to be clarified since mice lacking C3 generally have severely impaired antibody responses ${ }^{46}$.

Several other mechanisms to explain IgG-mediated immune suppression have been discussed. Central inhibition of B cells via co-crosslinking of BCR and the inhibitory $\mathrm{F}_{\mathrm{c}} \gamma \mathrm{RIIB}$ is hard to reconcile with efficient suppression in mice lacking this receptor ${ }^{10,13,32,33}$. Antigen modulation, i e that IgG after binding to an epitope removes it from the erythrocyte membrane via trogocytosis, is in principle similar to epitope masking and is compatible with many experimental observations. However, non-epitope specific suppression is hard to explain with this model because it would require that IgG anti-NP modulates also SRBC epitopes. This does not seem to happen because SRBC epitopes are still immunogenic in mice immunized with IgG anti-NP and SRBC-NP ${ }_{\text {high }}$ (Fig. 4D).

Clearance of erythrocytes from the blood has been suggested to play an important role in IgG-mediated immune suppression, but this hypothesis leaves many experimental findings unexplained. For example, $\operatorname{IgG}$ can be administered several days after SRBC (when the erythrocytes are already cleared from the circulation) and still abrogate an on-going antibody response $\mathrm{e}^{9,19,32,47}$. The most straightforward explanation for this is that the transfused IgG antibodies interfere with the interaction between specific B cells and SRBC, or SRBC fragments, still present in secondary lymphoid organs. This would lead to lack of continued B cell stimulation and result in the reported cessation of antibody production. Other observations not compatible with a major role for clearance are that the ability of IgG to suppress does not always correlate with the ability to induce clearance ${ }^{11,12,48-50}$. Moreover, after administration of IgG anti-SRBC and SRBC, an antibody response to the IgG molecule can be induced although the antibody response to SRBC is efficiently suppressed ${ }^{51,52}$. This would be hard to explain if the IgG-SRBC complexes were removed by clearance but would be expected after epitope masking. 
Whether animal models for IgG-mediated immune suppression of erythrocyte responses are relevant for the understanding of how anti-RhD prevents anti-D alloimmunization in humans is a matter of debate ${ }^{31,48,53}$. In spite of the obvious differences, there are also many similarities. Most importantly, antibody-mediated inhibition of antibody responses to intravenous foreign erythrocytes is studied in both situations. The fact that xenogeneic SRBC or allogeneic $\mathrm{RhD}^{+}$erythrocytes are the target antigens may not be as important a difference as postulated. Recent elegant experiments of IgG-mediated suppression in mice immunized with allogeneic erythrocytes (murine RBC expressing transgenic human blood group antigens) arrive at the same conclusions as experiments in mice immunized with SRBC: neither requires $\mathrm{Fc} \gamma \mathrm{Rs}^{10,13,15,32,33}$ nor clearance $\mathrm{e}^{11,12,48-50}$, there is an additive suppressive effect of several monoclonal antibodies recognizing different epitopes ${ }^{14,36}$, and polyclonal IgG preparations are more efficient than monoclonal IgG antibodies ${ }^{8,14}$. In humans there is no strict correlation between clearance and prevention of anti-D alloimmunization ${ }^{48,54,55}$ and, as mentioned above, several studies in mice arrive at the same conclusion ${ }^{11,12,49,50}$. Finally, anti-D administered after transfusion of $\mathrm{RhD}^{+}$erythrocytes ${ }^{56}$ as well as IgG anti-SRBC administered several days after SRBC $9,19,32,47$ effectively inhibit immunization. Attempts to find effective monoclonal or recombinant IgG anti-RhD antibodies to replace the polyclonal anti-D used in the clinic have had limited success ${ }^{55}$. Much of the search has been focused on Fc-related effector functions. Although it will be difficult, or even impossible, to determine exactly how well mouse models reflect the human situation, it may prove fruitful to assume that there is an overlap. This could prompt a search for anti-D antibodies with high affinity and the use of a mixture of antibodies recognizing different epitopes on the $\mathrm{RhD}$ antigen.

\section{Materials and Methods}

Mice. C57BL/6JBomTac mice (C57BL/6) from Taconic Bioscience, Inc (Hudson, NY, USA) were bred and maintained in the animal facilities at the National Veterinary Institute (Uppsala, Sweden). All mice were bred and maintained at the National Veterinary Institute (Uppsala, Sweden) under the supervision of a veterinarian. All experiments were approved by Uppsala Animal Research Ethics Committee and all experiments were performed in accordance with the relevant guidelines and regulations at Uppsala University. Mice were age (6-10 week old mice were used) and sex matched within each experiment.

Antigens and antibodies used for immunization. Polyclonal IgG anti-NP (allotype a) and IgG anti-SRBC (allotype a) were prepared from hyperimmune BALB/c serum immunized with BSA-NP 20 in Freund's complete adjuvant or $10 \%$ SRBC i.v. IgG from serum was isolated by affinity chromatography over a Protein-A Sepharose column (Amersham Pharmacia Biotech), dialyzed against PBS and stored at $-20^{\circ} \mathrm{C}$. SRBC were purchased from the National Veterinary Institute. For conjugation of SRBC-NP, 4-hydroxy-3-nitrophenylacetic-e-aminocaproyl-OSu (NP- $\varepsilon$-Aminocaproyl-OSu, Biosearch Technologies) was dissolved in dimethylformamide (Sigma-Aldrich) at a concentration of $7.5 \mathrm{mg} / \mathrm{ml}$. Appropriate amounts of this solution was added to $8 \mathrm{ml} 2.5 \%$ SRBC suspensions in conjugation buffer $\left(0.1 \mathrm{M} \mathrm{NaHCO}_{3}\right.$ with $\left.0.15 \mathrm{M} \mathrm{NaCl}, \mathrm{pH} 8.5\right)$ to a final concentration of 180,60 , or $20 \mu \mathrm{g} / \mathrm{ml}$ in order to achieve the coupling ratios referred to as SRBC-NP $\mathrm{Nigh}_{\text {h }}$ SRBC-NP $\mathrm{N}_{\text {int }}$ or SRBC-NP $P_{\text {low }}$. The mixture was incubated for $1 \mathrm{~h}$ at room temperature with gentle rotation. Cells were washed 3 times in PBS and stored in PBS up to two days before use.

Immunization and blood sampling. Mice were immunized with $30 \mu \mathrm{g}$ NP-specific polyclonal IgG (allotype a) in $200 \mu \mathrm{l} \mathrm{PBS}$, either alone or followed after $30 \mathrm{~min}$ by $5 \times 10^{7} \mathrm{SRBC}-\mathrm{NP}$ in $200 \mu \mathrm{l} \mathrm{PBS}$. Other groups were immunized with SRBC-NP or unconjugated SRBC alone. All immunizations were done intravenously in one of the lateral tail veins. Blood samples were collected from the ventral tail artery.

Enzyme-linked immunosorbent assay (ELISA). For all ELISAs, 96-well high binding plates

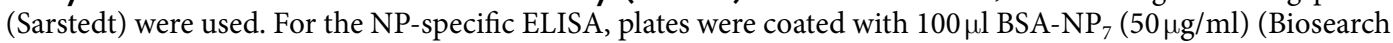
Technologies) in PBS with $0.05 \% \mathrm{NaN}_{3}$ at $4{ }^{\circ} \mathrm{C}$ overnight. Plates were blocked with $5 \%$ dry milk in $\mathrm{PBS}$ at $4{ }^{\circ} \mathrm{C}$ overnight. For the SRBC-ELISA, $50 \mu \mathrm{l}\left(25 \mu \mathrm{g} / \mathrm{ml}\right.$ in $\left.\mathrm{dH}_{2} \mathrm{O}\right)$ poly-L-lysine (Sigma-Aldrich) per well was added for $1 \mathrm{~h}$ at $37^{\circ} \mathrm{C}$. After washing twice in PBS, $100 \mu \mathrm{l} 0.25 \%$ SRBC in PBS was added to each well and left to settle at room temperature for $1 \mathrm{~h}$. The SRBC were fixed by gently immersing the plates in $0.25 \%$ glutaraldehyde in PBS (Sigma-Aldrich) for $10 \mathrm{~min}$. After washing 3 times in PBS, the plates were blocked with 5\% dry milk in PBS at $4{ }^{\circ} \mathrm{C}$ overnight. Immediately before use, plates were washed three times in PBS and $50 \mu \mathrm{l}$ of serum samples, serially diluted in dilution buffer $\left(0.05 \%\right.$ Tween, $0.25 \%$ dry milk and $0.02 \% \mathrm{NaN}_{3}$ in PBS). Plates were incubated overnight at $4{ }^{\circ} \mathrm{C}$. For detection of $\operatorname{IgM}, 50 \mu \mathrm{l}$ alkaline phosphatase-conjugated polyclonal goat anti-mouse IgM (Jackson ImmunoResearch Laboratories), 1:5000 in dilution buffer, was added to each well and incubated over night at $4{ }^{\circ} \mathrm{C}$. The next day, $100 \mu \mathrm{l}$ of the substrate $p$-nitrophenylphosphate (Sigma-Aldrich) was added and the absorbance at $405 \mathrm{~nm}$ was measured after $60 \mathrm{~min}$. For detection of IgG, an allotype-specific ELISA was used to allow distinction between the passively administered $\operatorname{IgG}^{\mathrm{a}}$ anti-NP and the endogenously produced $\operatorname{IgG}^{\mathrm{b}}$ anti-NP (this ELISA was also used to detect IgG anti-SRBC). Biotinylated anti-IgG1 ${ }^{\mathrm{b}}$ (clone B68-2) and anti-IgG2 $\mathrm{a}^{\mathrm{b}}$ (clone 5.7) (both from BD Pharmingen) were mixed 1:1, appropriately diluted in dilution buffer and $50 \mu \mathrm{l}$ was added to each well. Plates were incubated overnight at $4{ }^{\circ} \mathrm{C}$. After washing, $50 \mu$ l alkaline phosphatase-conjugated streptavidin (BD Pharmingen) in dilution buffer was added for $3 \mathrm{~h}$ at room temperature. After washing, $100 \mu \mathrm{l}$ of p-nitro-phenylphosphate (Sigma-Aldrich) was added. The absorbance at $405 \mathrm{~nm}$ was measured after $60 \mathrm{~min}$. Data was analyzed using SoftMax software (Molecular Devices).

Flow cytometry. Polyclonal IgG anti-NP (prepared as described above) was biotinylated using EZ-Link Sulfo-NHS-LC- LC-Biotin (sulfosuccinimidyl-6-biotinamido-6-hexanamido hexaonate) (Thermo Scientific) according to the manufacturer's instructions. To determine NP density, one million SRBC-NP in $50 \mu \mathrm{l}$ PBS were stained with $5 \mu \mathrm{g}$ of biotinylated IgG anti-NP at $4^{\circ} \mathrm{C}$ for $30 \mathrm{~min}$. After washing twice in PBS, phycoerythrin-conjugated streptavidin (eBioscience) was added and cells were stained for another $30 \mathrm{~min}$ at $4{ }^{\circ} \mathrm{C}$, 
washed twice in PBS, re-suspended in $300 \mu \mathrm{l}$ PBS and subjected to flow cytometry. Fifty thousand events were recorded for each sample. To detect NP-specific splenocytes, single cell suspensions in FACS buffer (PBS with $2 \%$ fetal bovine serum) were treated with Fc block (anti-CD16/32; BD Biosciences) on ice for 10 min before staining with B220-Alexa700 (clone RA3-6B2), anti-GL7-BV421 (clone GL7), anti-CD95-PEcy7 (clone Jo2), anti- $\lambda$ 1-biotin (clone R11-153) (all from BD Biosciences) at $4{ }^{\circ} \mathrm{C}$ for $30 \mathrm{~min}$. After washing, streptavidin-FITC (eBioscience) and NP-PE (Biosearch Technologies) was added. After incubation at $4{ }^{\circ} \mathrm{C}$ for $30 \mathrm{~min}$, samples were washed twice in FACS buffer and re-suspended in $300 \mu$ FACS buffer. Subsequently, 2-3 million events were recorded on a LSR Fortessa (BD Biosciences) at the BioVis platform, SciLifeLab, Uppsala, Sweden. Data was analyzed with FlowJo software (Tree Star Inc.).

Plaque forming cell assay (PFC). A modified version of the Jerne haemolytic plaque assay ${ }^{57}$ was used. Spleens were harvested 5 days after immunization and single cell suspensions prepared in Hank's balanced salt solution. One hundred $\mu \mathrm{l}$ of appropriately diluted spleen cells, $25 \mu \mathrm{l} 10 \%$ SRBC suspension, and $25 \mu l$ guinea pig serum (as a source of complement, diluted 1:10) (National Veterinary Institute) were added to $300 \mu 10.5 \%$ agarose at $45^{\circ} \mathrm{C}(50 \%$ Seaplaque agarose (low melting point, Amersham) and $50 \%$ agarose (United States Biochemical)). The mixture was immediately spread on a microscope slide and incubated in a humid chamber for $3 \mathrm{~h}$ at $37^{\circ} \mathrm{C}$. Hank's balanced salt solution were was used for all dilutions. Triplicate samples were counted "blindly".

Enzyme-linked immunospot assay (ELISPOT). Enzyme-linked immunospot assay (ELISPOT) was used to assess NP-specific IgM-secreting spleen cells. 96-well high binding plates (Sarstedt) were coated with $100 \mu \mathrm{l} \mathrm{BSA}-\mathrm{NP}_{7}(50 \mu \mathrm{g} / \mathrm{ml})$ in PBS with $0.05 \% \mathrm{NaN}_{3}$ and incubated overnight at $4^{\circ} \mathrm{C}$. The plates were washed twice in PBS and blocked with $5 \%$ dry milk at $4{ }^{\circ} \mathrm{C}$ overnight. After washing three times in PBS, spleen cells were serially diluted in cell culture medium (DMEM with $10 \%$ FCS). Hundred $\mu$ l was added to each well and plates incubated at $37^{\circ} \mathrm{C}$ for $18 \mathrm{~h}$. Fifty $\mu$ l goat anti-mouse IgM-alkaline phosphatase, (Jackson ImmunoResearch Laboratories), diluted 1:1000 in dilution buffer, was added and plates incubated for $3 \mathrm{~h}$ at room temperature. After washing three times with PBS, $100 \mu \mathrm{l}$ of the precipitating substrate 5-bromo-4-chloro-3-indolyl phosphate (Sigma-Aldrich) was added and plates incubated for $1 \mathrm{~h}$ at room temperature, washed three times in PBS and dried for $2 \mathrm{~h}$ at room temperature. Spots, representing IgM anti-NP producing cells, were counted blindly under a stereo-microscope.

Statistical analysis. Statistical differences between groups were determined by the two-tailed Student's $\mathrm{t}$-test. Statistical significance levels were set as: ns, $\mathrm{p}>0.05 ;{ }^{*} \mathrm{p}<0.05 ; * \mathrm{p}<0.01 ; * * \mathrm{p}<0.001$.

\section{References}

1. Heyman, B. Regulation of antibody responses via antibodies, complement, and Fc receptors. Annu. Rev. Immunol. 18, 709-737, https://doi.org/10.1146/annurev.immunol.18.1.709 (2000).

2. Nimmerjahn, F. \& Ravetch, J. V. Antibody-mediated modulation of immune responses. Immunol. Rev. 236, 265-275, https://doi. org/10.1111/j.1600-065X.2010.00910.x (2010).

3. Heyman, B. Antibodies as natural adjuvants. Curr. Top. Microbiol. Immunol. 382, 201-219, https://doi.org/10.1007/978-3-31907911-0_9 (2014).

4. Clarke, C. A. et al. Further experimental studies on the prevention of Rh haemolytic disease. Br. Med. Journal 1, 979-984, https://doi. org/10.1097/00006254-196112000-00017 (1963).

5. Urbaniak, S. J. \& Greiss, M. A. RhD haemolytic disease of the fetus and the newborn. Blood Rev. 14, 44-61, https://doi.org/10.1054/ blre.1999.0123 (2000)

6. de Haas, M., Thurik, F. F., Koelewijn, J. M. \& van der Schoot, C. E. Haemolytic disease of the fetus and newborn. Vox Sang 109, 99-113, https://doi.org/10.1111/vox.12265 (2015).

7. Henry, C. \& Jerne, N. Competition of $19 S$ and $7 \mathrm{~S}$ antigen receptors in the regulation of the primary immune response. J. Exp. Med. 128, 133-152, https://doi.org/10.1084/jem.128.1.133 (1968).

8. Heyman, B. \& Wigzell, H. Immunoregulation by monoclonal sheep erythrocyte-specific IgG antibodies: suppression is correlated to level of antigen binding and not to isotype. J. Immunol. 132, 1136-1143 (1984).

9. Möller, G. Antibody-mediated suppression of the immune response is determinant specific. Eur. J. Immunol. 15, 409-412, https:// doi.org/10.1002/eji.1830150420 (1985).

10. Karlsson, M. C., Wernersson, S., Diaz de Ståhl, T., Gustavsson, S. \& Heyman, B. Efficient IgG-mediated suppression of primary antibody responses in Fc gamma receptor-deficient mice. Proc. Natl. Acad. Sci. USA 96, 2244-2249, https://doi.org/10.1073/ pnas.96.5.2244 (1999)

11. Bergström, J. J., Xu, H. \& Heyman, B. Epitope-specific suppression of IgG responses by passively administered specific IgG: evidence of epitope masking. Front. Immunol. 8, 238, https://doi.org/10.3389/fimmu.2017.00238 (2017).

12. Yu, H. et al. Antibody-mediated immune suppression of erythrocyte alloimmunization can occur independently from red cell clearance or epitope masking in a murine model. J. Immunol. 193, 2902-2910, https://doi.org/10.4049/jimmunol.1302287 (2014).

13. Bernardo, L., Yu, H., Amash, A., Zimring, J. C. \& Lazarus, A. H. IgG-mediated immune suppression to erythrocytes by polyclonal antibodies can occur in the absence of activating or inhibitory Fc-gamma receptors in a full mouse model. J. Immunol. 195, 2224-2230, https://doi.org/10.4049/jimmunol.1500790 (2015).

14. Bernardo, L., Amash, A., Marjoram, D. \& Lazarus, A. H. Antibody-mediated immune suppression is improved when blends of antiRBC monoclonal antibodies are used in mice. Blood 128, 1076-1080, https://doi.org/10.1182/blood-2016-01-692178 (2016).

15. Liu, J. et al. Antigen modulation as a potential mechanism of anti-KEL immunoprophylaxis in mice. Blood 128, 3159-3168, https:// doi.org/10.1182/blood-2016-06-724732 (2016).

16. Smith, T. Active immunity produced by so-called balanced or neutral mixtures of diphtheria toxin and antitoxin. J. Exp. Med. 11, 241-260, https://doi.org/10.1084/jem.11.2.241 (1909).

17. Sinclair, N. R. S. C., Lees, R. K. \& Elliott, E. V. Role of the Fc fragment in the regulation of the primary immune response. Nature 220, 1048-1049, https://doi.org/10.1038/2201048a0 (1968).

18. Sinclair, N. R. S. C. Regulation of the immune response. I. Reduction in ability of specific antibody to inhibit longlasting IgG immunological priming after removal of the Fc fragment. J. Exp. Med. 129, 1183-1201, https://doi.org/10.1084/jem.129.6.1183 (1969).

19. Chan, P. L. \& StC. Sinclair, N. R. Regulation of the immune response. VI. Inability of $F\left(a^{\prime}\right) 2$ antibody to terminate established immune responses and its ability to interfere with IgG antibody-mediated immunosuppression. Immunology 24, 289-310 (1973). 
20. Brüggemann, M. \& Rajewsky, K. Regulation of the antibody response against hapten-coupled erythrocytes by monoclonal antihapten antibodies of various isotypes. Cell. Immunol. 71, 365-373 (1982).

21. Enriquez-Rincon, F. \& Klaus, G. G. B. Differing effects of monoclonal anti-hapten antibodies on humoral responses to soluble or particulate antigens. Immunology 52, 129-136 (1984).

22. Daëron, M. \& Lesourne, R. Negative signaling in Fc receptor complexes. Adv. Immunol. 89, 39-86, doi:S0065-2776(05)89002-9 (2006).

23. Heyman, B., Wiersma, E. \& Nose, M. Complement activation is not required for IgG-mediated suppression of the antibody response. Eur. J. Immunol. 18, 1739-1743, https://doi.org/10.1002/eji.1830181113 (1988).

24. Getahun, A. \& Heyman, B. Studies on the mechanism by which antigen-specific IgG suppresses primary antibody responses: evidence for epitope masking and decreased localization of antigen in the spleen. Scand. J. Immunol. 70, 277-287, https://doi. org/10.1111/j.1365-3083.2009.02298.x (2009).

25. Heyman, B. Non-determinant specificity of feedback immunosuppression by IgG antibodies injected after the antigen. Scand. J. Immunol. 27, 361-365, https://doi.org/10.1111/j.1365-3083.1988.tb02358.x (1988).

26. Tao, T. W. \& Uhr, J. W. Capacity of pepsin-digested antibody to inhibit antibody formation. Nature 212, 208-209, https://doi. org/10.1038/212208a0 (1966).

27. Cerottini, J. C., McConahey, P. J. \& Dixon, F. J. The immunosuppressive effect of passively administered antibody IgG fragments. J. Immunol. 102, 1008-1015 (1969).

28. Brody, N. I., Walker, J. G. \& Siskind, G. W. Studies on the control of antibody synthesis. Interaction of antigenic competition and suppression of antibody formation by passive antibody on the immune response. J. Exp. Med. 126, 81-91, https://doi.org/10.1084/ jem.126.1.81 (1967).

29. Sinclair, N. R. S. Fc-signalling in the modulation of immune responses by passive antibody. Scand. J. Immunol. 53, 322-330, https:// doi.org/10.1046/j.1365-3083.2001.00889.x (2001).

30. Heyman, B. et al. No evidence for a role of Fc gamma RIIB in suppression of in vivo antibody responses to erythrocytes by passively administered IgG. Scand. J. Immunol. 53, 331-334, https://doi.org/10.1046/j.1365-3083.2001.00890.x (2001).

31. Kumpel, B. M. \& Elson, C. J. Mechanism of anti-D-mediated immune suppression - a paradox awaiting resolution? Trends in Immunology 22, 26-31, https://doi.org/10.1016/S1471-4906(00)01801-9 (2001).

32. Karlsson, M. C., Getahun, A. \& Heyman, B. Fc gamma RIIB in IgG-mediated suppression of antibody responses: different impact in vivo and in vitro. J. Immunol. 167, 5558-5564, https://doi.org/10.4049/jimmunol.167.10.5558 (2001).

33. Bergström, J. J. \& Heyman, B. IgG suppresses antibody responses in mice lacking C1q, C3, complement receptors 1 and 2, or IgG Fc-receptors. Plos One 10, e0143841, https://doi.org/10.1371/journal.pone.0143841 (2015).

34. Jacob, J., Kelsoe, G., Rajewsky, K. \& Weiss, U. Intraclonal generation of antibody mutants in germinal centres. Nature 354, 389-392, https://doi.org/10.1038/354389a0 (1991).

35. Wiersma, E. J., Coulie, P. G. \& Heyman, B. Dual immunoregulatory effects of monoclonal IgG-antibodies: suppression and enhancement of the antibody response. Scand. J. Immunol. 29, 439-448, https://doi.org/10.1111/j.1365-3083.1989.tb01143.x (1989).

36. Quintana, I. Z., Silveira, A. V. \& Möller, G. Regulation of the antibody response to sheep erythrocytes by monoclonal IgG antibodies. Eur. J. Immunol. 17, 1343-1349, https://doi.org/10.1002/eji.1830170919 (1987).

37. Dennert, G. The mechanism of antibody-induced stimulation and inhibition of the immune response. J. Immunol. 106, 951-955 (1971).

38. Murgita, R. A. \& Vas, S. I. Specific antibody-mediated effect on the immune response. Suppression and augmentation of the primary immune response in mice by different classes of antibodies. Immunology 22, 319-331 (1972)

39. Song, H. \& Cerny, J. Functional heterogeneity of marginal zone B cells revealed by their ability to generate both early antibodyforming cells and germinal centers with hypermutation and memory in response to a T-dependent antigen. J Exp Med 198, 1923-1935, https://doi.org/10.1084/jem.20031498 (2003).

40. Cerutti, A., Cols, M. \& Puga, I. Marginal zone B cells: virtues of innate-like antibody-producing lymphocytes. Nat Rev Immunol 13, 118-132, https://doi.org/10.1038/nri3383 (2013).

41. Wason, W. M. Regulation of the immune response with antigen specific IgM antibody: a dual role. J. Immunol. 110, 1245-1252 (1973).

42. Karlsson, M. C. I., Diaz de Ståhl, T. \& Heyman, B. IgE-mediated suppression of primary antibody responses in vivo. Scand. J. Immunol. 53, 381-385, https://doi.org/10.1046/j.1365-3083.2001.00886.x (2001).

43. Walker, J. G. \& Siskind, G. W. Studies on the control of antibody synthesis. Effect of antibody affinity upon its ability to suppress antibody formation. Immunology 14, 21-28 (1968).

44. Heyman, B. \& Pilström, L. Primary and secondary IgG antibodies are equally efficient immunosuppressors in relation to antigen binding capacity. Immunology Letters 17, 189-194, https://doi.org/10.1016/0165-2478(88)90090-9 (1988).

45. Junghans, R. P. \& Anderson, C. L. The protection receptor for IgG catabolism is the beta-2-microglobulin-containing neonatal intestinal transport receptor. Proc. Natl. Acad. Sci. USA 93, 5512-5516 (1996).

46. Fischer, M. B. et al. Regulation of the B cell response to T-dependent Ags by classical pathway complement. J. Immunol. 157, 549-556 (1996)

47. Finkelstein, M. S. \& Uhr, J. W. Specific inhibition of antibody formation by passively administered 19S and 7S antibody. Science 146, 67-69, https://doi.org/10.1126/science.146.3640.67 (1964).

48. Beliard, R. Monoclonal anti-D antibodies to prevent alloimmunization: lessons from clinical trials. Transfus. Clin. Biol. 13, 58-64, https://doi.org/10.1016/j.tracli.2006.03.013 (2006).

49. Brinc, D., Le-Tien, H., Crow, A. R., Freedman, J. \& Lazarus, A. H. IgG-mediated immunosuppression is not dependent on erythrocyte clearance or immunological evasion: implications for the mechanism of action of anti-D in the prevention of haemolytic disease of the newborn? Br. J. Haematol. 139, 275-279, https://doi.org/10.1111/j.1365-2141.2007.06764.x (2007).

50. Marjoram, D. et al. Immunoglobulin G Fc glycans are not essential for antibody-mediated immune suppression to murine erythrocytes. Blood, https://doi.org/10.1182/blood-2017-06-793729 (2017)

51. Brinc, D. et al. Transfusion of antibody-opsonized red blood cells results in a shift in the immune response from the red blood cell to the antibody in a murine model. Transfusion 50, 2016-2025, https://doi.org/10.1111/j.1537-2995.2010.02645.x (2010).

52. Bergström, J. J. E. \& Heyman, B. Mice immunized with IgG anti-sheep red blood cells (SRBC) together with SRBC have a suppressed anti-SRBC antibody response but generate germinal centers and anti-IgG antibodies in response to the passively administered IgG. Front. Immunol. 8, 911, https://doi.org/10.3389/fimmu.2017.00911 (2017).

53. Cruz-Leal, Y., Marjoram, D. \& Lazarus, A. H. Prevention of hemolytic disease of the fetus and newborn: what have we learned from animal models? Curr. Opin. Hematol. 24, 536-543, https://doi.org/10.1097/MOH.0000000000000374 (2017).

54. Stegmann, T. C. et al. RhIg-prophylaxis is not influenced by FCGR2/3 polymorphisms involved in red blood cell clearance. Blood 129, 1045-1048, https://doi.org/10.1182/blood-2016-05-716365 (2017).

55. Kumpel, B. M. Lessons learnt from many years of experience using anti-D in humans for prevention of RhD immunization and haemolytic disease of the fetus and newborn. Clin. Exp. Immunol. 154, 1-5, https://doi.org/10.1111/j.1365-2249.2008.03735.x (2008).

56. Pollack, W., Ascari, W. Q., Crispen, J. F., O’Connor, R. R. \& Ho, T. Y. Studies on Rh prophylaxis. II. Rh immune prophylaxis after transfusion with Rh-positive blood. Transfusion 11, 340-344 (1971).

57. Jerne, N. K. \& Nordin, A. A. Plaque formation in agar by single antibody-producing cells. Science 140, 405, https://doi.org/10.1126/ science.140.3565.405 (1963). 


\section{Acknowledgements}

We thank Annika Westin and Zhoujie Ding for skilful technical assistance. This work was supported by Uppsala University, The Swedish Research Council, China Scholarship Council (CSC), Ellen, Walter, and Lennart Hesselman's Foundation, Hans von Kantzow's Foundation, King Gustaf V:s 80 Years Foundation, Ollie and Elof Ericsson's Foundation, and Agnes and Mac Rudberg's Foundation. The flow cytometric analyses was performed on instruments provided by the BioVis platform at SciLifeLab, Uppsala University.

\section{Author Contributions}

H.X. and B.H. designed the experiments and wrote the manuscript. H.X. and L.Z. performed the experiments. All authors reviewed the manuscript.

\section{Additional Information}

Supplementary information accompanies this paper at https://doi.org/10.1038/s41598-018-33087-6.

Competing Interests: The authors declare no competing interests.

Publisher's note: Springer Nature remains neutral with regard to jurisdictional claims in published maps and institutional affiliations.

(c) (i) Open Access This article is licensed under a Creative Commons Attribution 4.0 International License, which permits use, sharing, adaptation, distribution and reproduction in any medium or format, as long as you give appropriate credit to the original author(s) and the source, provide a link to the Creative Commons license, and indicate if changes were made. The images or other third party material in this article are included in the article's Creative Commons license, unless indicated otherwise in a credit line to the material. If material is not included in the article's Creative Commons license and your intended use is not permitted by statutory regulation or exceeds the permitted use, you will need to obtain permission directly from the copyright holder. To view a copy of this license, visit http://creativecommons.org/licenses/by/4.0/.

(C) The Author(s) 2018 